Filosofia 



\title{
Habermas e Heidegger: uma discórdia filosófica ${ }^{1}$
}

\author{
BARBARA FREITAG ROUANET ${ }^{I}$
}

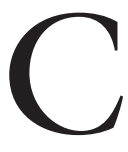

ONFESSO que não tive oportunidade de conhecer, em vida, o professor paraense Benedito Nunes, filósofo, crítico literário, ele mesmo escritor e profundo conhecedor da cultura brasileira e universal. O contato com sua vasta obra e o aprofundamento pela leitura de seu pensamento sui generis constituíram-se, no entanto, em uma boa surpresa e insuspeitada recompensa para mim, indicada para ocupar, depois de sua morte, a cadeira número 8 da Academia Brasileira de Filosofia (ABF). Sua produção literária filosófica reveloume uma afinidade eletiva com a maioria dos temas e autores aos quais deu atenção. Essa afinidade foi maior no campo literário, suscitando imediata simpatia e despertou certo ceticismo com relação às suas preferências no campo da filosofia, no qual não consigo partilhar o seu entusiasmo pelo pensamento de Martin Heidegger, algo que tentarei justificar no decorrer de minha argumentação.

De Benedito Nunes li primeiro a sua obra $O$ dorso do tigre (ensaios literários e filosóficos) (Nunes, 1969), segui lendo A passagem para o poético e depois me debrucei em seu livro Ensaios filosóficos em que retoma Heidegger, aborda Hannah Arendt, Hegel, Nietzsche, Paul Ricoeur, Foucault e Sartre, entre outros filósofos (Nunes, 2010). Sua familiaridade e valorização de autores como Clarice Lispector, João Cabral de Melo Neto, Guimarães Rosa, Fernando Pessoa confirmaram e reforçaram em mim a "queda" especial por cada um desses autores e incentivaram minha curiosidade a ponto de procurar alargar meus conhecimentos sobre eles e suas obras.

Para ilustrar minhas preferências literárias gostaria de destacar, a título de exemplo, meu encanto pelas reflexões que Benedito Nunes fez sobre o amor, baseado na obra de Guimarães Rosa - Grande sertão: veredas - em que focaliza três espécies diferentes de amor com os quais o jagunço Riobaldo é confrontado: o enlevo por Otacília, a moça encontrada na Fazenda Santa Catarina; a flamejante e dúbia paixão pelo amigo Diadorim; e a voluptuosa recordação de Nhorinha, prostituta versada em artes mágicas... Benedito Nunes comenta magistralmente essas formas de amor recorrendo à filosofia:

A relação entre essas três espécies de amor, diferentes formas ou estágios de um mesmo impulso erótico, que é primitivo e erótico em Diadorim, sensual em Nhorinha e espiritual em Octacília, traduz um escalonamento semelhante ao da dialética ascensional, transmitida por Diotima a Sócrates em O Banquete de Platão... eleva-se, gradualmente do sensível ao inteligível, do corpo à alma, da carne ao espírito, num perene esforço de sublimação... 
Em outro tópico, dessa vez sobre a viagem, Nunes exalta "as práticas do imaginamento" de Guimarães Rosa como as expressões "a rosação das roseiras", "o coqueiro coqueirando" e assim por diante. Vide "A viagem do Grivo" (uma das estórias de Corpo de baile de Guimarães Rosa). Aqui Benedito Nunes elucida: "A viagem tem dois sentidos e versões: a narrativa propriamente dita e a narrativa da narrativa, em que GRIVO, personagem central, desempenha a função narradora: é ele que liga 'Coração de Bronze' às coisas, ligando o patrão (doente e paralítico) ao povo que povoa Urubuquáquá...”, e Nunes e conclui: "O relato das coisas vistas e imaginadas durante o percurso, a viagem, transforma em palavras, súmula da atividade poética que abriu os espaços do sertão, e os converteu na profusão do mundo natural e humano...".

Por razões de espaço e tempo, terei de deixar de lado análises igualmente pertinentes e belas deixadas por Benedito Nunes como as que fez sobre Fernando Pessoa, sobre João Cabral de Melo Neto, em especial em João Cabral: a máquina do Poema (Nunes, 2007), ou sobre a obra de Clarice Lispector, que ele conheceu pessoalmente na Amazônia, e cuja obra leu e acompanhou desde o início, dedicando um livro denso e profundo sobre sua "écriture" com recurso a Heidegger, como testemunha seu livro O drama da linguagem. Uma leitura de Clarice Lispector (Nunes, 1989). Todos os seus estudos e ensaios literários mereceriam um tratamento extra e bem mais aprofundado, mas como não sou crítica literária, darei ênfase especial às minhas preferências filosóficas.

\section{A origem da discórdia filosófica entre Habermas e Heidegger}

Devo confessar que meu contato com o pensamento filosófico de Benedito Nunes gerou uma certa cautela epistêmica, que merece ser tematizada, apesar de ele conquistar minha admiração pela seriedade e coerência com que se apoderou do pensamento de Heidegger. Isso certamente exigiu um grande esforço, particularmente para dominar os conceitos desenvolvidos em "Sein und Zeit" $(1927)^{2}$ e os escritos da segunda e terceira fases desde as "Carta sobre o Humanismo" tinham lacunas e omissões. O meu ceticismo avolumou-se, no entanto, com outro contratempo, que aflige todos o heideggerianos contemporâneos: o lançamento de uma "Gesamtausgabe" (obras completas) editadas a partir da década de 1960 pela Editora Klostermann de Frankfurt/M. Como esse espólio estava até então em poder dos herdeiros (a mulher, Elfriede, e o filho Herrmann Heidegger), estão sendo lançados textos até então desconhecidos (que antes foram guardados a sete chaves) mas que finalmente o próprio Heidegger (1889-1976) autorizou publicar depois de sua morte. Trata-se de textos escritos a partir de 1931-1976, que ele mesmo chamou de "Die schwarzen Hefte" ("Cadernos Negros", dos quais ainda falarei para encerrar minha apresentação).

Admito que meu ceticismo com relação a Heidegger teve sua origem na Alemanha. Muitos dos meus professores e colegas alemães desenvolveram certas reservas sobre sua obra a partir do anos 1950. No Brasil, contudo, tais reservas pareciam não existir, ou não foram consideradas, como foi o caso de Benedito 
Nunes e vários filósofos brasileiros de sua geração, como Carneiro Leão, Ernildo Stein e tantos outros, que tentaram familiarizar-se com sua obra. Um caso especial foi o de Fausto Castillo, que dedicou trinta anos da sua vida para estudar alemão, voltou a estudar grego e latim e confessou ter sido obrigado a recriar sua competência gramatical e linguística do português para lançar a edição bilíngue de Sein und Zeit - Ser e tempo de Heidegger, em São Paulo (2012). Simplesmente trabalho e estudo de toda uma vida! Procurado pela TV paulista, Castillo não encontrou palavras para a pergunta que agora aflige a todos: A adesão de Heidegger ao "movimento" nacional-socialista durante os anos 1930/1945 e seu antissemitismo explícito teriam contaminado seu pensamento e sua obra? Sua filosofia teria escamoteado a percepção do Holocausto e contribuído para a "shoa" nos campos de extermínios na Europa, comandados por Hitler? (cf. Entrevista dada no YouTube, em 2012).

Por que eu nunca aderi aos "heideggerianos" alemães ou brasileiros? Não foi falta de interesse pela filosofia ou dificuldades com a língua alemã. $O$ alemão é minha "Muttersprache", minha língua materna, a língua que mesmo no Brasil sempre falei com minha mãe, que a cultivou como "Sprache der Dichter und Denker", herdada de Goethe, Schiller, Kant, Hegel, Freud e Marx, e que li com fascinação crescente no decorrer de minha formação cultural e acadêmica.

Durante os meus estudos de Sociologia, Psicologia e Filosofia na Universidade de Frankfurt, e depois, em Berlim, na Freie Univesität (1961-1967), falar de Heidegger e sua obra não era considerado "politicamente correto". Nossas leituras, Seminários e trabalhos de Curso versavam sobre temas weberianos (em parte por consideração a seu centenário de nascimento de Max Weber): a Sociologia das Religiões, Economia e Sociedade, a neutralidade das ciências em geral e das Ciências da Sociedade em especial, a objetividade da pesquisa social e do Conhecimento. Theodor W. Adorno e Max Horkheimer, diretores do Institut für Sozialforschung, tinham acabado de voltar dos Estados Unidos para onde haviam fugido da perseguição nazista na década de 1930, perdendo seus cargos e funções, seus livros e bens, sendo obrigados a recomeçar a vida. Tratava-se de vida difícil na costa leste (New School e em Nova York) e oeste (Universidade de Berkeley e Los Angeles dos Estados Unidos), onde centenas de cientistas sociais e naturais, judeus, comunistas, liberais haviam buscado alternativas de vida. Contudo, à luz da redemocratização na Europa e da emergência do macartismo nos Estados Unidos, preferiram voltar para a Alemanha, apesar de dividida em quatro "Besatzungszonen" (áreas de ocupação dos aliados, vencedores da guerra). Muitos dos emigrados criavam coragem para voltar à futura Bundesrepublik Deutschland, de preferência àquela "BZ" dos vencedores ingleses, americanos e democráticos. A parte ocupada pelas tropas francesas a partir de 1945 foi a Região da Floresta Negra, onde se encontrava a Universidade de Freiburg/i. Br. e onde até essa data "reinava" Martin Heidegger. Ali ele foi nomeado Reitor (1933/1934) e posteriormente acusado de colaborador com o regime nazista. 
Em sua fala de posse ("Rektoratsrede"), seus cursos, suas aulas e em discursos públicos, Heidegger tentou ganhar a adesão dos estudantes em favor da "grandeza do movimento" (subentendido "o movimento nazista") e "a verdade interior" desse movimento. O "Comitê de Desnazificação da Universidade Alemã", instalado pelos aliados, decidiu afastá-lo temporariamente de sua função docente, impedindo-o de publicar sua obra. Em termos brasileiros, Heidegger foi "cassado" e proibido de escrever ou falar em público entre 1945-1951. Mesmo assim, e talvez por isso mesmo, sua obra exercia forte atração sobre descendentes de emigrantes na Argentina, no Brasil e outros países latino-americanos, que passaram a mandar depois de finda a Segunda Guerra Mundial seus filhos para Freiburg, respirar a aura do "mestre". ${ }^{3}$

Pude matricular-me em Frankfurt, na Johann Wolfgang Goethe Universität em 1961, por ser alemã e dominar a língua, matrícula facilitada pelo fato de que parte da família materna que não emigrou como nós para o Brasil (1948) ainda vivia perto de Frankfurt.

Já no início de minha graduação, recebi “dicas” de colegas segundo as quais eu deveria assistir aos cursos e seminários de Horkheimer, Adorno, Habermas. Entre outras ofertas fui alertada para acompanhar uma pesquisa empírica de importância: Student und Politik, coordenada por Habermas et al. (1961). Essa pesquisa levantou dados sobre a consciência política dos universitários que retomaram os estudos na cidade natal de Goethe, na maioria filhos de nazistas, buscando conhecer suas motivações, seu eventual antissemitismo, seus preconceitos racistas, seu potencial democrático, revolucionário. A pesquisa estava inspirada no estudo do qual participara Adorno na Califórnia, intitulado "A personalidade autoritária" (1950), que por sua vez retomava as pesquisas empíricas sobre "Autoridade e família", iniciada na década de 1930 no Institut für Sozialforschung por Horkheimer, Marcuse, Pollock, Wittvogel e outros, interrompida com o advento do nacional-socialismo e a perseguição dos judeus na Europa. Desse modo aprendemos, no dia a dia universitário, a aplicar os testes da F-Scala (Escala de Fascismo), fazer entrevistas e interpretações dos dados no estilo da "Teoria crítica", que veio caracterizar a depois chamada "Escola de Frankfurt".

Paralelamente, assisti a aulas de Horkheimer sobre a Filosofia do Iluminismo e Teoria do Esclarecimento, Teoria e Prática dos meios de Comunicação (nos Estados Unidos), Propaganda política e Técnicas de pesquisa. Em cursos especiais, assistíamos a filmes nazistas para nos familiarizarmos com as técnicas de doutrinação antissemita e História Contemporânea que mostravam a vida e a morte dos detentos em Campos de Concentração e de Extermínio (de milhares de judeus, comunistas, ciganos, e estrangeiros) a partir de 1939.

Friedrich von Friedeburg deu continuidade a esses estudos e técnicas em uma ampla pesquisa entre estudantes de Berlim ocidental, na Freie Universität, razão para muitos de nós solicitarmos a transferência de nossa matrícula de Frankfurt para Berlim (Ocidental), depois de Adorno (1969) e Horkheimer 
(1972) se aposentarem. Nesse clima que deu origem aos movimentos estudantis de Rudi Dutschke e do franco-alemão Cohn-Bendit, não havia "campo" nem vez para a filosofia hermenêutica ou existencialista de Heidegger. A partir do final da década de 1950, este voltou a se manifestar, reeditando suas aulas dos anos 1930/1940 e reformulando suas ideias de "Sein und Zeit" em uma "Spätphilosophie", registrada em sua carta ao Humanismo, dirigida a um colega francês Jean Beaufret. A leitura ocasional de "O que é a metafísica?" ou "O que é a verdade?", questões sobre "Sein", "Seyn", "Da-Sein", "In-die-Welt-Geworfen-Sein" nos pareciam mais jogos de palavras do que preocupações autênticas em torno da reconstrução das cidades em ruínas, das famílias dizimadas na e pela guerra, da "Wiedergutmachung" (reparações materiais, espirituais, morais) dos sobreviventes do Holocausto.

Theodor W. Adorno nos divertia com suas análises linguísticas em "Jargon der Eigentlihkeit" (Adorno, 1964) ${ }^{4}$ que em verdade faziam uma crítica feroz ao jargão heideggeriano mas que para nós, geração "pós-heideggeriana”, passavam a sensação do conto de Hans Christian Andersen: "Des Kaisers'neue Kleider", em que uma criança exclama inocentemente: "Mas o imperador está nu!".

Certamente éramos uma geração irreverente e parte dela até mesmo "revolucionária" como a RAF (Rote Armee Franktion), que marcou o "movimento de maio de 1968", bem diferente daquele, intencionado pelos nazistas, mas tão radical, que Habermas chegou a falar em "fascismo de esquerda", quando foram queimados livros diante do Institut für Sozialforschung. ${ }^{5}$ Para nós, até sua morte (1969) e bem além, Theodor W. Adorno passou a ser o modelo do pensamento filosófico crítico aderindo à sua "Dialética da Ilustração", "Dialética Negativa", "Aesthetische Theorie". Ouvíamos suas falas na Rádio e TV sobre "Theorie der Halbbildung", "Nie wieder Auschwitz" e tentávamos obter cópias das músicas dodecafônicas nos moldes de Berg e Schönberg, que compunha para melhor entendermos sua Teoria e crítica da Música, como último reduto de protesto contra a sociedade contemporânea.

Max Horkheimer nos encantava com seus cursos sobre os clássicos gregos, dos pré-socráticos, aos diálogos platônicos, da Paideia à Ética de Nicômaco, dos autores de epopeias e tragédias, de Homero a Sófocles e Eurípides. O mundo cinzento das ruínas das cidades bombardeadas de Frankfurt ou Berlim, em fase de reconstrução, parecia iluminar-se. Die Vernunft, a Razão, trazia a promessa da entrada da Luz nas trevas, nos fazia reconhecer a loucura que foram as guerras, apontando para as chances de redenção da culpa histórica que nossos pais nos deixaram como herança. Horkheimer insistia no resgate da razão e na "AUFKLÄRUNG" que como em português tinha um sentido duplo: "clarear" (o mau tempo) e "esclarecer" as dúvidas que o passado recente nos impusera.

Quando Herbert Marcuse $(1968)^{6}$ vinha da Califórnia, animava-nos durante os chamados "Universitätstage", falando do "Homem unidimensional" mas também de "Eros e Civilização", da retomada do amor, e fazia crítica aos 
excessos de repressão e recalque que a cultura burguesa das sociedades capitalistas e socialistas impunha aos indivíduos da contemporaneidade. Marcuse, antigo orientando de doutorado de Heidegger, esclarecia ainda que havia trocado cartas com Heidegger (no final da década de 1940), cobrando-lhe explicações quanto ao seu envolvimento com os nazistas desde 1933 e o reconhecimento da culpa dos alemães, sugerindo que fizesse - em nome do povo dos poetas e pensadores alemães inocentes - um pedido de desculpas por ter sido omisso diante do Holocausto que marcou o assassinato de milhões de pessoas durante a Segunda Guerra Mundial. Mas como pudemos ler em uma carta-resposta de Heidegger a Marcuse, isso não aconteceu... ${ }^{7}$

A lição para compreender a razão de ser da moderna filosofia, e de nossa atuação em um mundo democrático em que nazismo, antissemitismo e Holocausto NUNCA mais teriam lugar, estava dada e nossa tarefa definida: Cultivar a Razão, a Democracia e a Tolerância; continuar desenvolvendo a Teoria Crítica, superar todas as formas de "totalitarismo"; festejar o casamento da filosofia com a sociologia, associar a Teoria com estudos empíricos e nunca dissociar a Teoria da Prática, algo que Habermas sintetizou em seu livro Erkenntnis und Interesse (1973), e em toda sua produção posterior, ou seja, praticar a filosofia e os estudos das Ciências Humanas no interesse da "Emancipação dos seres humanos", livre de todos os males do passado recente.

Jürgen Habermas, ${ }^{8}$ o assistente de Adorno na década de 1950/1960 em Frankfurt, época em que tinha pouco mais de vinte anos, foi o que melhor incorporou essas ideias. Ele foi o primeiro a publicar (no jornal Frankfurter Allgemeine Zeitung - FAZ) uma crítica severa a Heidegger, que resumirei mais adiante.

Na década de 1970 Habermas passou uma temporada na New School em Nova York, centro de estudos e pesquisa também frequentado por Hannah Arendt, Hans Jonas, Richard Bernstein, entre outros. Essa experiência valeu-lhe o conhecimento dos filósofos americanos, dos quais se tornaria colega, amigo e interlocutor nas décadas seguintes: Richard Rorty, John Rawls, Lawrence Kohlberg, e outros, abrindo os horizontes de várias outras disciplinas como a Psicologia, a Linguística, o Direito, a Sociologia (vide Talcott Parsons e C. W. Mills, Searle, Austin) para a Teoria Crítica. Habermas voltou e permaneceu na Alemanha, onde assumiu, na década de 1980, a cátedra de Filosofia no Institut für Sozalforschung e depois do Departamento de Filosofia da J. W. Goethe Universität de Frankfurt, como seu modelo e predecessor Theodor W. Adorno.

Anos depois, Florestan Fernandes solicitou-me contribuir para sua Coleção de Cientistas Sociais com um volume sobre um grande pensador alemão vivo. Foi uma excelente oportunidade de estabelecer um contato pessoal com Habermas em Starnberg (perto de Munique), que deu origem à coletânea que Sergio Paulo Rouanet e eu publicamos, Habermas, pela editora Ática (1980). Depois disso, mantive uma correspondência regular com Jürgen Habermas, as- 
segurando vários encontros, entrevistas e a elaboração de três números da $R e^{-}$ vista Tempo Brasileiro em homenagem ao seus 60, 70 e 80 anos. Acompanhei sua produção teórica, que resenhei, critiquei e comentei no livro Dialogando com Habermas (2005). Esse livro contém as duas entrevistas que Sergio Paulo Rouanet e eu fizemos com ele (1989 e 1995). Baseada nesses diálogos, gostaria de resumir, a seguir, algumas ideias centrais da obra de Jürgen Habermas destiladas da "Teoria da Ação Comunicativa", do seu "Discurso filosófico da Modernidade", e de sua Ética do Discurso, publicada em português sob o título Democracia e direito. ${ }^{9}$

\section{A Teoria da Modernidade de Habermas}

Em sua Teoria da ação comunicativa (1981), Habermas desenvolveu uma "Teoria da Modernidade" calcada em um novo conceito de razão, a razão comunicativa. A sua teoria parte de um conceito de sociedade que abrange a óptica do "sistema" (visão objetiva, externa, da sociedade) e a óptica do "mundo vivido" (visão subjetiva, interna); ao mesmo tempo o autor procura explicar a gênese da moderna sociedade ocidental, diagnosticar suas patologias e buscar soluções para a sua supressão e superação. A Teoria da Ação Comunicativa vai além das teorias evolutivas simplificadoras de um Auguste Comte, Spencer e Darwin por compreender os processos de transformação das formações societárias como processos coletivos de aprendizagem. À semelhança dos processos da psicogênese infantil (Piaget), as sociedades modernas têm capacidade de aprender e alargar cada vez mais seus horizontes, reestruturando sua consciência social, moral, linguística e racional. Assim sendo, as sociedades superam processos de organização mais simples e menos eficazes em favor de processos mais universais, mediante sucessivas descentrações. Nessa forma de evolução "superam” os princípios de organização do parentesco, do mercado (organizado em torno do trabalho e do capital), do Estado (nacional) em direção ao Estado supranacional, mediante a introdução de processos argumentativos, baseados em "discursos” que buscam novas soluções, chegando a novas descentrações. As novas formações societárias cada vez mais complexas aprendem a implementar sucessivamente princípios de universalização que permitem maior diferenciação e autonomização das diferentes esferas societárias.

A passagem de um patamar de estruturação em torno de um princípio de organização para o seguinte vem acompanhado de crises. A descentração de um padrão de organização significa via de regra o desprendimento de um princípio particular em favor de um princípio de maior universalidade.

Segundo Habermas, a "modernidade" refere-se às formações societárias do nosso tempo; dos "tempos modernos", marcados por três eventos históricos ocorridos na Europa: a reforma Protestante; o Iluminismo e a Revolução Francesa. Assim Habermas localiza a "Modernidade" no tempo (século XVIII ao XXI) e no espaço (Ocidente, ou seja, a Europa). Fazem parte dessa "modernidade" as sociedades de classe do capitalismo liberal e "tardio" ("Spätkapitalismus") e 
as sociedades de classe do socialismo de Estado ("Staatskapitalismus"), duas variantes de formações societárias de classe, diferenciadas em Estado e Economia.

Habermas distingue os processos de modernização sistêmica (racionalização do Estado político e da Economia de Mercado) dos processos de modernização cultural, que estariam se dando no interior do "mundo da vida" (Lebenswelt) e abrangendo as esferas de valor da moral, da ciência e da arte das quais falava Weber. Assim, afirma que o mundo sistêmico é regido pela racionalidade instrumental, necessária para a reprodução material da vida na sociedade. $\mathrm{O}$ mundo sistêmico dispensa a ação comunicativa pois recorre ao dinheiro no interior dos subsistema econômico; enquanto o subsistema do Estado recorre ao poder. É no contexto do "mundo da vida" que sobreviveu a razão comunicativa, baseada na ação comunicativa, que recorre à argumentação e ao discurso e promove a reprodução simbólica da sociedade. Aqui podem ser questionados os valores da arte, da moral e da ciência, nichos societários que (ainda) permitem buscar autonomia e defender a emancipação, por seu grau de liberdade historicamente conquistado. Enquanto o mundo sistêmico garante a "integração sistêmica", o mundo da vida garante a "integração social". No primeiro, a racionalidade e a ação instrumental são hegemônicas; no segundo, a ação e a racionalidade comunicativa ditam as regras. Como Habermas vê no sistema uma forma necessária de sobrevivência, pode-se argumentar que esses dois subsistemas da formação societária moderna têm função de "redução de complexidade" (Luhmann"), pois não é possível renegociar todas as relações sociais permanentemente a partir da estaca zero. A introdução da perspectiva do "mundo da vida" (Lebenswelt) permite através da razão comunicativa, recorrer à linguagem para argumentar contra ou a favor de certas patologias que a sociedade (pós ou trans-) moderna possa apresentar. É através da fala quotidiana que podemos introduzir "questionamentos" e fazer valer "aspirações de validade" (Geltungsansprüche) sobre a verdade das afirmações, a correção (Richtigkeit) das regras aplicadas e a veracidade do nosso interlocutor. Não é através da mentira sobre os fatos, o desrespeito às regras do jogo ou a falta de idoneidade moral que chegaremos a corrigir e superar as crises de nossas sociedades. Em tribunais de pequenas causas já foi demonstrado que o entendimento pode ser obtido entre as partes conflitantes à base de bons argumentos, "abrindo o jogo" e não escondendo a verdade, não enganando o "outro" com mentiras e omissões, e respeitando as regras já comprovadas e democraticamente estabelecidas. Resumindo...

A Teoria da Modernidade de Habermas refere-se, pois, a uma série de transformações ocorridas no passado mais recente das formações societárias, dando destaque a quatro tipos de processos: os processos de diferenciação (Ausdifferenzierung), de racionalização (Rationalisierung), de autonomização (Autonomisierung) e de dissociação (Entkoppelung). Enquanto a diferenciação e a autonomização têm uma conotação positiva, os processos de racionalização e de dissociação ganham uma conotação negativa. A diferenciação traduz um 
aprendizado coletivo. A autonomização significa o desprendimento relativo de um subsistema, uma estrutura ou esfera do conjunto societário, permitindo o seu funcionamento à base de princípios autônomos, mais ou menos adequados para aquele subsistema, estrutura ou esfera. É o caso da "autonomização" da esfera da ciência, que se libera das amarras impostas por convicções religiosas, estruturando-se em torno do princípio da verdade, sem prestar contas às outras esferas o que ocorre em seu interior. Fiel à etimologia original da palavra, a autonomização significa um ganho relativo de liberdade das "esferas", subsistemas ou estruturas em questão.

A racionalização refere-se a processos de transformação institucional segundo a racionalidade instrumental. Predomina o cálculo da eficácia: os meios são ajustados a fins. Para a obtenção de um fim determinado, impõe-se o uso dos meios mais eficazes, com um mínimo de gastos (de tempo, material, pessoa) e efeitos colaterais indesejados, e um máximo de benefícios desejados (lucro, poder etc.). A eficácia em termos de menores custos para maiores benefícios passa a ser um fim em si mesmo. A racionalização tem, para Habermas, conotação negativa, porque expulsa dos espaços em que age a razão argumentativa, a racionalidade comunicativa que permitiria a negociação coletiva dos fins, dos "últimos fins", do próprio processo de transformação societária.

A Entkoppelung (literalmente desengate/desprendimento, dissociação), por sua vez, faz que os homens modernos submetam as suas vidas às leis do mercado e à burocracia estatal como se fossem forças estranhas contra as quais não há nada a fazer. Muitas crises provocadas pelo Estado são percebidas - equivocadamente - como catástrofes da natureza (o "Geschick" ou destino de Heidegger) contra as quais nada se pode fazer.

É contra essa atitude que Habermas propõe lutar e corrigir a modernidade. Antes de poder ser compreendida, será necessário "destruir e descontruir" visões equivocadas da Modernidade, como transmitidas pelos ensaios da "Spätphilosophie" de Heidegger, que falava sem rodeios do nacional-socialismo como de um movimento "com uma verdade e grandeza intrínsecas" em tom de um "profeta incendiário" (ver sua crítica de 1953 na $F A Z$ ). Nessa sua crítica e revolta contra Heidegger, o jovem Habermas já se perguntava:

Será possível que o assassinato planejado de milhões de pessoas, sobre o qual nós hoje todos estamos informados, ainda pode ser apresentado como um pequeno engano? Esse assassinato não seria um crime ("Verbrechen") factual daqueles que o cometeram - e a má consciência de todo um povo (o alemão)? Será que não bastaram esses oito anos que tivemos desde (1945) para que pudéssemos enfrentar o risco de um debate e esclarecimento com aquilo que foi, que fomos? Não seria agora a nossa tarefa de esclarecer essas ações de nossa responsabilidade com relação a esse passado? E deixarmos acesa a chama do conhecimento desses crimes e dessa responsabilidade? ...

Em vez disso, Heidegger continua, com as mesmas palavras de antes, agora já envelhecidas, reeditar, sem alterações (um texto de 1935). 
Em 1985, no seu livro crítico contra os pós-estruturalistas, e dedicado à sua filha Rebekka, Der philosophische Diskurs der Moderne, Habermas (1985) exprime sua irritação contra Heidegger por "ele jamais ter admitido seu erro, demonstrando má vontade e incapacidade de dizer, mesmo que seja com uma frase, sua corresponsabilidade (no Holocausto), apoiando o movimento nacional-socialista". Ele não somente permaneceu silencioso até a morte (em 1976), mas chegou a atribuir a causa e a culpa do Holocausto às próprias vítimas, os judeu, usando o termo de "Selbstvernichtung" (autodestruição).

Em 1987, referindo-se às revelações críticas de Hugo Ott e Victor Farias contra essa atitude de Heidegger, Habermas fala em "recalque" dessa culpa, procurando desprender suas ações do contexto histórico como pessoa empírica e atribuí-las ao "Geschick" ou Schicksal (destino) abstrato, inocentando os indivíduos e atores concretos emaranhados nessa trama. Heidegger não somente negou e inverteu esses fatos históricos como escamoteou informações, transformando-se ele próprio em vítima. Habermas conclui seu ensaio contido em "O Discurso filosófico da modernidade" com a pergunta implacável: "Como Heidegger pôde compreender a história do Ser do movimento nacional-socialista como manifestação da verdade?". Já na Introdução para o livro de Victor Farias: Heidegger und der Nationalsozialismus, 1987/1992, Habermas ainda mais crítico chega à convicção de que havia uma relação íntima entre a obra e a pessoa de Martin Heidegger.

\section{Post-scriptum: Die schwarzen Hefte: "Much adoo about nothing"?}

No final dos anos 1960 a editora Klostermann de Frankfurt comprou de Martin Heidegger os direitos de editar uma Gesamtausgabe, ou seja uma edição completa de todos seus textos. No final de 2013 a editora e a imprensa livre surpreenderam o mercado livreiro divulgando uma nota segundo a qual a edição estava se aproximando de seus últimos volumes. A partir de 2014 apareceram nas livrarias os volumes $94,95,96,97,98$, e possivelmente já estão sendo lançados os volumes 99 e 100 ainda no primeiro semestre deste ano de 2015. Estes últimos volumes estão saindo da gráfica sob a responsabilidade de uma comissão presidida pelo professor Peter Trawny, da Faculdade de Filosofia da Universidade de Wuppertal, Universidade à qual está vinculado o Instituto de Pesquisa Martin Heidegger. O anúncio de 2013 da editora chamou a atenção para um fato inesperado. Os últimos nove volumes contêm a transcrição de 34 cadernos de notas, que o próprio Martin Heidegger batizou de "Schwarze Hefte" (Cadernos negros). As anotações começam em 1931 e terminam com a morte de Heidegger em 1976. Esses cadernos tinham sido entregues aos editores com a ressalva de que somente poderiam ser publicados, no conjunto da Gesamtansgabe, depois da morte do filósofo, cuja família administrava o espólio do homem considerado o maior filósofo do século XX. Peter Trawny, o atual editor e conhecedor profundo das obras reunidas de Heidegger, deixou vazar algumas passagens das mais chocantes. Os textos já editados e impressos que 
chegaram ao nosso conhecimento (a público) confirmam todas as suspeitas sobre o colaboracionismo de Heidegger com os nazistas e todos os seus preconceitos raciais contra os judeus ao quais passa a atribuir sem grandes rodeios a culpa de sua própria extinção nas câmeras de gás em Auschwitz. Nos tais cadernos Heidegger reafirma sua concepção do "Führerstaat", glorifica o povo alemão, como eleito para salvar a Europa ("Abendland") esmagada entre o capitalismo anglo-saxônico e o comunismo soviético, declara o seu "Denken" como herdeiro da verdadeira filosofia, que teve suas origens nos pré-socráticos, idealiza o poeta Hölderlin, como o novo Messias, que de certa forma antecipou a vinda do Messias Salvador (Hitler). Enfim, Heidegger dá razão aos seus críticos e fornece os comprovantes explícitos de tudo que eles já haviam destacado à luz de sua obra anterior (impressa), entre os quais Theodor W. Adorno, Jürgen Habermas, Herbert Marcuse, Hugo Ott (1988), Victor Farias, Lucien Faye (2005). O que antes era suspeita, agora é certeza! O próprio Heidegger fornece sob forma de manuscritos (secretos) as "provas" autênticas de seu envolvimento com o nazismo, usando a filosofia para mascarar suas ambições de poder.

Assim como a Segunda Guerra gerou o "Historikerstreit" do qual Habermas participou sempre defendendo a razão comunicativa, agora haverá uma reedição do "Heideggerstreit" que ocupará as mentes, os computadores, os Programas de TV (YouTube) e dará trabalho às editoras, reanimará o movimento editorial, lançará a obra de Heidegger sob a forma de e-book e tornará célebres aqueles que elogiarão as "roupas novas do Imperador", de fato desmascarado.

Até agora a imprensa sensacionalista abriu um debate que somente poucos podem seguir, pelo mero fato de nem tudo estar publicado, e o que está publicado na Gesamt-Aausgabe-Heidegger está em alemão.

Os comentaristas do Feuilleton da Neue Züricher Zeitung, sempre comedidos, somente agora se assustaram com os termos usados por Heidegger em seus Cadernos negros, publicando manchetes como "O negro da alma de Heidegger", "Ainda é possível ler Heidegger?”, "A última cartada do Mágico", e assim por diante. O Semanário alemão Die Zeit reuniu em uma folha as versões mais explícitas e agressivas de Heidegger contra o que este chamou de "guerra do judaísmo mundial" ("Weltjudentum") contra os alemães ou "Rachsucht" (surtos doentios de vingança), dos aliados, demonstrando a validade do mecanismo psíquico descoberto por Freud, da Projeção, ou seja, projetar no outro as próprias animosidades, agressividades e desejos de morte.

O mundo acadêmico mostrou mais competência e cautela na condenação ou defesa de Martin Heidegger (1889-1976). O mais competente, ao qual tive acesso, pareceu-me o Colóquio "Heidegger et les 'juifs'”, organizado no final de janeiro deste ano de 2015 na Biblioteca Nacional de Paris e do qual participaram a Universidade de Paris, Estrasburgo, Casa da Irlanda, a TV ARTE, entre outras... ${ }^{11}$

O filósofo Bernard-Henri Levy, no encerramento do Colóquio em Paris, 
diferente do alarde da imprensa e vozes ferozes CONTRA ou até mesmo em favor da proibição da leitura da sua obra (como sugere L. Faye), disse que devemos incentivar essa leitura e promover o debate, fazendo-nos PENSAR sobre a razão de ser da Filosofia, sua função no contexto das sociedades contemporâneas e sobre seus riscos e erros, dos quais a controvérsia sobre Heidegger é o melhor exemplo. E aqui - nesta CASA - A Academia Brasileira de Filosofia - é o melhor lugar e ambiente para travar este debate!

Rio de Janeiro, 29 maio 2015

\section{Notas}

l O presente texto (aqui na íntegra) foi apresentado (sob forma reduzida) em minha posse na Academia Brasileira de Filosofia (ABF), Rio de Janeiro, no dia 29 de junho de 2015, ocupando a cadeira n.8, anteriormente ocupada por Benedito Nunes.

2 Martin Heidegger, Sein und Zeit (com a dedicatória na primeira edição para o seu orientador "Edmund Husserl in Verehrung und Freundschaft zugeeignet"). Todnauberg im Bad Schwarzwald, 8.4.1926, Jahrbuch für Philosophie und phänomenologische Forschung, Band VIII); edição utilizada: Max Niemeyer, Tübingen: Verlag, 1979 -17. ed. revista (sem a dedicatória a Husserl).

3 Cf. entrevista do hoje catedrático professor Herrmann no Philosophisches Quartett de Sloterdijk, 2011, na televisão alemã Zweites Deutsches Fernsehen. Das inúmeras biografias escritas sobre Heidegger, retomei as seguintes: Biemel (1973), lembrando o $70^{\circ}$ Aniversário do filósofo; Rentsch (1989); Safranski (1994).

4 A mesma editora publicou as obras completes do autor em vinte volumes (Adorno, 1972-1980). Ver também a obra conjunta com Max Horkheimer. Dialektik der Aufklärung, Philosophische Fragmente, Amsterdam (1.ed. pirata, 1947).

5 Ver a Revista do Instituto editada por Max Horkheimer: Zeitschrift für Sozialforschung, em nove volumes (edição fac-símile, DTV reprint) (München: Köselvelag, 1980).

6 Tese originalmente orientada por Heidegger.

7 Para Victor Farias (ver em: Heidegger e o nacional-socialismo, 1989, p.374-5), essa justificativa e desculpa nunca foi dada. Ele transcreve uma troca de cartas entre Heidegger e Marcuse, ex-aluno de Heidegger, que não deixam dúvidas quanto às atitudes cautelosas do mestre, depois de 1946, em que ambos discorrem sobre o envolvimento heideggeriano em favor do nazismo e seu antissemitismo disfarçado. Em carta de 20.1.1948, Heidegger se justifica diante de seu antigo discípulo já radicado em Berkeley na Califórnia, com as seguintes passagens que cito: "1 Eu esperava do Nacional-socialismo uma renovação espiritual da vida, um apaziguar das contradições sociais e uma salvação do ocidente (Abendland) diante dos perigos do comunismo (o que tentara mencionar em sua 'Rektoratsrede', durante a posse no cargo de reitor na Universidade de Freiburg)...; 21934 reconheci meu erro político e acabei pedindo demissão do cargo de Reitor (um ano depois)...; 3 O Senhor tem toda razão em criticar a falta, de uma confissão pública minha contrária ao regime nazista ("Gegenbekenntnis"), mas isso teria sido a minha morte e a de minha família...; 4 Em meus cursos e minhas aulas de 1934/44, assumi uma posição tão inequívoca, que nenhum dos meus alunos (universitários) se viu forçado a aderir ao nazismo [...] o que os meus textos, uma 
vez publicados, comprovarão; 5 Uma confissão depois de 1945 não me foi possível, pois os nazistas que aderiram ao movimento confessavam de um modo tão asqueroso a sua mudança de atitude e mentalidade, que eu não queria identificar-me com eles; 6 Diante de suas pesada e justificadas acusações sobre o regime que matou milhões de judeus, que transformou o terror em normalidade, revertendo em seu contrário tudo que se expressa nos conceitos verdade, liberdade e espírito, somente gostaria de acrescentar, que em lugar de 'judeus' teria que estar escrito 'Ost-Deutsche', valendo assim para qualquer aliado, com a diferença de que tudo que acontece desde 1945 se tornou público a todo mundo, enquanto o terror sangrento dos nazistas permaneceu segredo diante do povo alemão" (citado em Victor Farias, p.374-5, tradução minha)

8 Como vou basear toda a minha argumentação subsequente em um coletânea minha sobre Habermas, intitulada Dialogando com Habermas (Freitag, 2005), remeto o leitor interessado nos títulos originais e em tradução brasileira a esse volume, poupando-me, assim, o trabalho cansativo de repetir cada obra neste pequeno resumo sobre sua obra e essa série de artigos meus tentando reunir trinta anos de debate com o autor da Teoria da Ação Comunicativa e a sua Teoria da modernidade, que contêm a maior parte da bibliografia do filósofo alemão ainda vivo (em alemão e em português).

9 Exprimo aqui meus agradecimentos especiais ao casal Portella e à TB responsáveis pela ampla divulgação dos debates dos livros e cursos da Jürgen Habermas com seus críticos e seguidores. Ver também os textos de Flávio Benno Siebeneichler sobre Habermas e sua tradução de "Faktizität u.Geltung" como "Democracia e Direito" (Rio de Janeiro: Edição Tempo Brasileiro, 1996); e ainda os três números especiais da Revista Tempo Brasileiro, comemorando o $60^{\circ}$, o $70^{\circ}$ e o $80^{\circ}$ aniversário de Habermas, reunindo autores brasileiros e internacionais, comemorando o pensamento de Jürgen Habermas.

10 Até agora (final do primeiro semestre de 2015) a editora Vittorio Klostermann, em Frankfurt am Main, publicou (capa dura) seis volumes, cada um contendo aproximadamente 400 páginas, com uma nota explicativa do editor Peter Trawny no final de cada volume e textos de segunda e quarta capa, resumindo os procedimentos da transcrição, numeração e subtítulos de cada um dos 34 cadernos. Como "Überlegungen” (reflexões), “Anmerkungen”, (notações), "Winke” (indicações), "Vorläufiges" (provisórios), "Notturno" (noturno) etc.

11 Na Alemanha, a Universidade de Siegen, a DFG, organizou uma Conferência Internacional intitulada "Philosophia e Política: Martin Heideggers schwarzen Hefte" (22-25 de abril de 2015).

\section{Referências}

ADORNO, T. W. Jargon der Eigentlichkeit. Zur deutschen Ideologie. Frankfurt/a.M.: Suhrkamp Verlag, 1964.

Gesammelte Schriften. Frankfurt/a.M.: Suhrkamp Verlag, 1972-1980.

BIEMEL, W. Heidegger, Bildmonographien. Rowohlt: Taschenbuchausgabe, Hamburg, 1973.

FAYE, E. Heidegger: Líntroduction du nazisme dans la Philosophie (autour des Seminaires inédits 1933-1935). Paris: Albin Michel, 2005.

FREITAG, B. Dialogando com Habermas. Rio de Janeiro: Tempo Brasileiro, 2005. 
HABERMAS, J. Der philosophische Diskus der Moderne. Frankfurt/Main: Suhrkampverlag, 1985.

HABERMAS, J.; FRIEDEBURG, F. von. et al. Student und Politik. Eine soziologische Untersuchung zum Bewusstsein Frankfurter Studenten. Neuwied: Hermann Luchterhand Verlag, 1961.

MARCUSE, H. Hegels Ontologie und die Theorie der Geschichtlicheit. Frankfurt: Vittorio Klostermann, 1968.

NUNES, B. O dorso do tigre. Debates e críticas. São Paulo: Perspectiva, 1969.

1989.

O drama da linguagem. Uma leitura de Clarice Lispector. São Paulo: Ática,

- João Cabral: a máquina do poema. Brasília: Ed. UnB, 2007.

. Ensaios filosóficos. Org. e apres. Victor Sales Pinheiro. São Paulo: Martins Fontes, 2010.

OTT, H. Martin Heidegger. Unterwegs zu seiner Biographie. New York: Campus; Frankfurt: Verlag, 1988.

RENTSCH, T. Martin Heidegger: Das Sein und der Tod. Eine kritische Einführung. Münche-Zürich: Piper Verlag, 1989.

SAFRANSKI, R. Ein Meister aus Deutschland. Heidegger und seine Zeit. München-Wien: Karl Hanser Verlag, 1994.

RESUMO - Benedito Nunes enquanto crítico literário baseou parte de suas interpretação dos textos de Clarice Lispector, Guimarães Rosa, Drummond e outros na obra Ser e tempo, de Martin Heidegger. Tomamos tal fato como ponto de partida para situar o pensamento de Heidegger no contexto da Segunda Guerra Mundial e seu envolvimento com o nacional-socialismo. O seu texto remete a um dos maiores críticos de Heidegger, o filósofo e sociólogo Jürgen Habermas, o primeiro a criticar, seguido de Marcuse, Adorno, Hugo Ott, Victor Farias e mais recentemente Emmanuel Faye, a atuação do autor de Sein und Zeit, enquanto professor e reitor da Universidade de Freiburg entre 1931-1945. Se Habermas, em sua crítica de 1953, ainda separara a filosofia de Heidegger do homem e cidadão, a partir de 1992 acaba convencido de que o antissemitismo e a adesão aberta de Heidegger ao partido nazista já permeavam, desde o início, sua obra filosófica. A recente (2013-2015) publicação dos chamados "Cadernos Negros" de Heidegger nos volumes 94, 95, 96, 97 e 98 nas Obras completas hoje, não deixam dúvida de que essa interpretação é correta, algo que Benedito Nunes, que faleceu em 2011 , não podia saber.

PALAVRAS-CHAVE: Filosofia, Crítica literária, Nacional-socialismo, Antissemitismo, Existencialismo, Nihilismo, História alemã.

ABSTRACT - As a literary critic, Benedito Nunes based some of his interpretations of texts by Clarice Lispector, Guimarães Rosa, Carlos Drummond de Andrade and others on Heidegger's Being and time. Freitag takes this fact as a starting point to place Heidegger's thought in the context of World War II and of his involvement with Nazism. Toward this end, she relies on J. Habermas' criticism of Heidegger (supported 
by other critics, including Marcuse, Adorno, Ott, V. Farias and E. Faye) to assess the crucial issue of whether or not it is possible to separate the philosopher from the human being as a common citizen. With this in mind, she pays special attention to Heidegger's recently published Black notebooks (Shwarze Hefte).

KErWORDS: Philosophy, Literary criticism, Nazism, Anti-Semitism, Existentialism, Nihilism, Recent German history.

Barbara Freitag Rouanet nasceu na Alemanha em 1941 e passou sua infância no Brasil. Estudou sociologia e filosofia no Institut Für Sozialforschung, em Frankfurt, na Alemanha, com Horkheimer, Adorno e Habermas, e terminou sua formação acadêmica em Berlim. Lecionou durante mais de trinta anos no Brasil (Universidade de Brasília). Entre seus livros teóricos vale mencionar: Teoria crítica: ontem e hoje, Os itinerários de Antígona, Dialogando com Jürgen Habermas, Teorias da cidade e Cidade e literatura. @ - bfreitag@uol.com.br

I Academia Brasileira de Filosofia, Rio de Janeiro/Rio de Janeiro, Brasil.

Recebido em 14.6.2015 e aceito em 18.7.2015. 
